To cite this article: Joan Domènech-Abella, Jordi Mundó, Marta Miret, José Luis Ayuso-Mateos, Albert Sánchez-Niubò, Adel S. Abduljabbar, Josep Maria Haro \& Beatriz Olaya (2019): From childhood financial hardship to late-life depression: socioeconomic pathways, Aging \& Mental Health

To link to this article: https://doi.org/10.1080/13607863.2019.1671313

\title{
From childhood financial hardship to late-life depression: socioeconomic pathways.
}

\begin{abstract}
Objective: Childhood financial hardship is associated with depression throughout the lifecourse, including older adulthood. However, it is still unclear the extent to which occupation, education level and household income are mediators of this association. We aimed to examine the association between childhood financial hardship and late-life depression, and potential socioeconomic mediators using community-based data.

Methods: A nationally representative sample of 3,623 non-institutionalized older Spanish adults aged $50+$ was used. The associations between childhood financial hardship and depression, socioeconomic mediator variables and cofounding variables such as chronic physical conditions, number of close people, and loneliness, were assessed through logistic regression models. Mediation analyses of socioeconomic variables were carried out.

Results: Older Spanish adults who experienced a poor childhood financial situation were 9 times more likely to obtain a lower level of education than those with a good childhood financial situation, and about 3 times more likely to suffer from depression. Participants' education level mediated about $35-40 \%$ of the association between childhood financial hardship and late-life depression whereas we found no significant mediation effect of household income and occupation skill.
\end{abstract}


Conclusion: Improving access to the educational system during the life-course might result in a reduction in the prevalence of depression in the general population of older adults and particularly among individuals with low SES.

Keywords: Childhood SES, intergenerational social mobility, depression, Spain

\section{From childhood financial hardship to late life depression: socioeconomic pathways.}

\section{Introduction}

The involvement of social, economic and environmental factors in the configuration of physical and mental health has been widely recognized (Marmot, 2005; Allen et al., 2014). The experience and impact of social determinants vary throughout life and influence people of different genders and at different stages of life in a particular way. Several authors agree on highlighting the need to focus on the issue, taking the life course into account, in order to understand and address health inequalities (Elovainio et al., 2016; Kendig et al., 2016; Pudrovska et al., 2014).

Although current life course research lacks an integrated perspective, several complementary models have been developed (Ben-Shlomo and Kuh, 2002). One of these, called the "critical period", is based on the premise that adverse tensions at various stages of life, such as the fetal stage and early childhood, can directly alter development processes and determine adulthood health (Glover, 2015; Najman et al., 2004). However, according to the social pathways model, the effects of a low childhood socioeconomic status (SES) on adult health may also be mediated through adult socio-economic position (Luo and Waite, 2005). Several investigations also show that the effects of childhood socioeconomic environment on adult health are context-dependent and vary according to country and different social, political and economic structures (Conroy et al., 2010; Galobardes et al., 
2004), which could contribute to explaining differences in mental health among European countries (Ploubidis and Grundy, 2009).

Major depressive disorder (MDD) is one of the most common disorders among older adults (Byers et al., 2010). In Spain, the prevalence of depression in the general population is $10.6 \%$ and, when compared with younger cohorts, the population over 50 years of age presents a greater risk of depression, with a prevalence of 12.6\% (Gabilondo et al., 2010). Aging is associated with biological and social changes that constitute risk factors for depression, such as widowhood, functional impairment, mild cognitive deterioration, and loneliness, with special intensity among individuals with a low socio-economic status (SES) (Djernes, 2006; Koster et al., 2006). Depression has a significant impact on older populations and is linked to higher risk of suicide, all-cause mortality and increasing health service use (Blazer, 2003).

Nevertheless, the association between the financial situation of children and depression in later life has been little studied but the results obtained so far are revealing. One study on the effect of childhood SES on depression and other physical and mental disorders during young adulthood (25 years old) in New Zealand concluded that, although most disorders were predicted by childhood SES, this association was not observed for depression (Poulton et al., 2002). Conversely, other studies found that low childhood SES increases the likelihood of major depression during young adulthood independently of sociodemographic factors, family history of mental illness, and adult SES (Gilman et al., 2003, 2002). Another study focused on mid-adulthood (from 40 to 45 years old) in the UK reported that the effect of childhood socio-economic position on adult depressive disorders was mediated by adult socio-economic position (Stansfeld et al., 2008), and that adverse SES in childhood was associated with poorer older adult health, including greater 
depression symptomatology, independently of adult social position and diverse measures of disease risk and physical and mental functioning (Power et al., 2007).

One of the few studies on the association between socioeconomic situation during childhood and depression in late life, documented a positive association, particularly pronounced for women, between childhood SES and symptomatology of depression among older adults even after adjusting for contemporaneous SES (Angelini et al., 2018). Another study among older Japanese people reported this association even after adjustments for current disease status, health behaviors, and social relationships. This study also detected a weaker association among the oldest of the old, maybe due to a survival effect (Tani et al., 2016).

Given the importance and extent of this correlation in contemporary societies, the objective of this study is to measure the proportion of the association between childhood financial hardship and depression among older adults explained by their current SES. We previously found that different SES dimensions (household income, education level and occupation skills) were independently associated with depression in older adults (Domènech-Abella et al., 2018). Thus, we further explored the mediational role of these three SES dimensions. We tested the following hypothesis: 1) Age and sex modify the association between childhood financial hardship and older adult depression; 2) childhood financial hardship is associated with adult SES (education, household income and occupation skills), and 3) the association between childhood financial hardship and late life depression is mediated by household income, education level and occupation skills to different degrees. 


\section{Methods}

\section{Study Design}

This study was part of the Collaborative Research on Ageing in Europe (COURAGE in Europe) project (Leonardi et al., 2014), a European funded, cross-sectional survey of a non-institutionalized adult population (aged $\geq 18$ years) conducted between April 2011 and May 2012. A total of 4,752 participants were interviewed in Spain: 961 (18-49 years), 3,312 (50-79 years) and 479 (80+ years). To achieve appropriate representation of the Spanish population, a stratified multistage clustered area probability method was used. The Spanish Statistical Office provided a list of households, and individuals were randomly selected within the household by the interviewer. Subgroups $50+$ and $80+$ years were oversampled, given that these individuals were the main target of the study. The survey response rate was $69.9 \%$.

Face-to-face structured interviews were carried out at respondents' homes using Computer-Assisted Personal Interviewing (CAPI). The survey questionnaire was initially developed in English and then translated into Spanish following World Health Organization translation guidelines for assessment instruments. Quality assurance procedures were implemented during fieldwork (Leonardi et al., 2014). When individuals had severe cognitive impairment, judged at the interviewer's discretion, a shorter version of the questionnaire was administered to a proxy.

For the current analyses, we excluded proxy respondents $(n=168)$. Individuals aged $<50$ years $(n=962)$ were also excluded. Thus, the final analytical sample comprised 3,623 participants. 


\section{Ethics statement}

Ethical approval for the COURAGE study Spain was provided by Parc Sanitari Sant Joan de Déu, Barcelona, Spain, and Hospital la Princesa, Madrid, Spain. Informed consent was obtained from the participants.

\section{Measures}

We took previous literature into account when choosing confounding variables in the association between childhood financial difficulties and late life depression, mediated by education level, household income, or occupation. Some researchers reported differences by gender (Angelini et al., 2018) and age groups (Tani et al., 2016). In addition to subsequent socio-economic difficulties, adverse socioeconomic conditions during childhood were also found to lead to risk behaviors for mental and physical health (Clark et al., 2009, Stansfeld et al., 2008) and were related to poorer cognitive development and emotional problems that trigger health risk behaviors and relational problems (Glover, 2015; Najman et al., 2004).

Participants were asked to provide socio-demographic and socio-economic information: age, categorized into 50-64, 65-79 and 80+, gender, education level, occupation, household income, financial situation during childhood, social network (number of close people and feelings of loneliness) and health status (physical chronic conditions, major depressive episode (MDE) during the previous year and depression before the age of 50).

Categories for highest level of education completed were "no formal education", primary, secondary (secondary or high school) and tertiary (university degree). Participants were asked about their highest level of occupation throughout their life. Occupation was defined using ISCO 08 categories (European Union, 2009), which were classified into three 
levels according to their skill requirements following International Labor Organization (2008) criteria: "high" (skill level $3+4$ ) corresponding to managers, senior officials and legislators, professionals, technicians and associate professionals; "medium” (skill level 2) corresponding to clerks, service and sales workers, skilled agricultural and fishery workers, craft and related trades workers, plant and machine operators, and assemblers; and "low" (skill level 1) corresponding to elementary occupations such as office cleaners, freight handlers, garden laborers and kitchen assistants (International Labour Organization, 2008).

Respondents were asked about household income through written statements and marking their best estimates of total household income on scales provided, including income from wages or stipends from a job as well as income from unemployment benefit, pensions, investments, and aid to families or other government or nongovernment benefits during the previous 12 months. The amount obtained was divided by household size, determined after applying the following weights: 1.0 to the first adult, 0.5 to each other household member aged 14 or over and 0.3 to each household member aged under 14 years old (Eurostat, 2016). Finally, since the association between household income and depression may not be strictly linear (Domènech-Abella et al., 2017), the variable was divided into quartiles.

Participants were also asked about the financial situation during childhood [i.e., "How would you describe your family's financial situation during your childhood?']. The possible responses were "Very good", "good", "average", "bad" and "very bad". Very good and good were unified in the same category.

Loneliness was assessed by means of the three-item UCLA Loneliness Scale (Hughes et al., 2004), which consists of the following items: "How often do you feel that you lack companionship?"; "How often do you feel left out?”; "How often do you feel isolated from 
others?". Each item was answered on a 3 -point scale $(1=$ hardly ever; $2=$ some of the time; 3 = often). The UCLA Loneliness Scale has shown satisfactory reliability and both concurrent and discriminant validity (Hughes et al., 2004). The scores for each item were added up to produce a loneliness scale from 3 to 9 , with higher scores indicating a greater degree of loneliness. In the present study, the 3-item UCLA Loneliness Scale showed good internal reliability (Cronbach's alpha $=0.89$; average inter-item correlation $=0.72$ ).

Size of the social network was assessed by asking about the number of people in the network [i.e., "Please state the number of people (in total) who are so close to you at the present time that you: can talk to them about personal affairs, can get help from them in everyday matters, and/or enjoy spending your leisure time with them (please consider family members, friends, colleagues, etc.)"]. The variable was categorized into "None", "1 to $2 ", " 3$ to $5 "$ and "more than $5 "$ ".

Chronic medical conditions were based on self-report diagnoses of chronic obstructive lung disease, asthma, hypertension, arthritis, stroke, angina pectoris and diabetes in the previous 12 months. Additionally, symptom algorithms were used to detect undiagnosed cases of arthritis, stroke, angina, chronic lung disease, and asthma (Garin et al., 2016). The presence of hypertension was based on self-report diagnosis or presence of systolic blood pressure $\geq 140 \mathrm{mmHg}$ or diastolic blood pressure $\geq 90 \mathrm{mmHg}$ measured at the time of the interview (Basu and Millett, 2013; Mancia et al., 2013). Participants were considered to have a chronic medical condition if there was presence of either a diagnosed or undiagnosed condition. From those measures, we constructed the chronic conditions variable with "0", "1", "2"or "more than 2" as categories.

We used a set of questions about symptoms derived from an adapted version of the World Health Organization Composite International Diagnostic Interview (CIDI) (Kessler 
\& Ustün, 2004) to assess the presence of MDD in the previous 12 months. The CIDI is a fully-structured interview designed to be used by trained lay interviewers to assess mental disorders according to ICD-10 and DSM-IV criteria. An algorithm based on the DSM-IV (American Psychiatric Association, 2013; Garin et al., 2016) was used to determine whether a participant had MDD in the previous year .

Participants also answered the question "Have you ever been diagnosed with depression?", and if yes, they were then asked "How old were you the first time you were diagnosed with depression?" We classified participants into self-reported depression before and after the age of 50 .

\section{Statistical analysis}

Unweighted frequencies and weighted proportions were used for descriptive analyses. Participants with and without 12-month MDD were compared using the RaoScott $\chi^{2}$ test for categorical variables and one-way ANOVA test for continuous variables.

Logistic regression models were conducted to explore the associations between childhood financial situation and presence of 12-month MDD (dependent variable). Interactions between childhood financial situation and age or sex were tested. We first explored unadjusted models to determine raw odds ratios (ORs) for each covariate. Next, socio-economic variables (education level, household income, occupation skill and childhood financial situation) were introduced simultaneously into the model. Subsequently, a fully adjusted model was run with all the covariates (age groups, gender, number of physical chronic conditions, depression diagnosed before reaching 50 years old, number of close people and loneliness). Unadjusted ordered logistic regression models were also fitted to evaluate the association between childhood financial situation and education level, household income and occupation level, separately. In the case of 
occupation level, participants in the "never worked" category were interpreted as missing data in order to keep this variable as ordinal.

To assess the possible mediation of each socioeconomic variable in the association between childhood financial situation and late life MDD (see Figure 1), mediational analysis was performed using the $K H B$ command (Breen et al., 2013; Karlson et al., 2012; Karlson and Holm, 2011) through Stata version 13.1 (StataCorp, 2013). It decomposes the total effect of a variable into direct and indirect (i.e., mediational) effects. This method also allows for the calculation of the mediated percentage, which represents the percentage of the main association that can be explained by the mediator. Since mediation models are linear regression models, the total, direct and indirect (or mediated) effects of the independent variable on dependent variable were reported in beta coefficients. The total effect $(100 \%)$ is the sum of the direct and indirect effects. The percentages were obtained comparing the coefficients. The mediated percentage was only considered significant when both the total and indirect effects were significant. Models were adjusted for covariates (age groups, gender, number of physical chronic conditions, depression diagnosed before reaching 50 years old, number of close people and loneliness). For categorical variables, the effects for each category compared with the category of reference are reported.

The statistical analysis took into account the stratified study design. Poststratification corrections were made to the weights to adjust for the population distribution obtained from the national census and for non-response (Moussavi et al., 2007). About 30\% of individuals did not complete some of the variables. We cannot be certain about the reasons for the missing data, but no major discrepancy was found between imputed data and complete-case analysis so we are leaning towards imputed data as missing at random. Missing values were imputed using multiple imputation by chained equations through the 
predictive mean matching method (White et al., 2011). The imputation model included important sociodemographic and health-related variables associated with drop-outs (see supplementary material, Table S1). Thirty imputed databases were created. The number of imputations was calculated using a rule of thumb with respect to the fraction of missing information (M>100*FMI) (Rubin, 2004). All analyses were performed using Stata version 13 for Windows (SE version 13, College Station, TX). A $p$-value less than 0.05 was considered to be statistically significant.

\section{Results}

The socio-demographic characteristics of the study sample are presented in Table 1. About $12 \%$ of participants reported MDD in the last year. Statistically significant differences between people with and without 12-month MDD were found; individuals suffering from MDD in the last year were more frequently women, reported more feelings of loneliness, had none or few close people, had a higher number of chronic conditions, were more likely to have a diagnosis of depression before the age of 50 and showed a lower level in all socioeconomic dimensions, including those who never worked.

Table 2 shows hierarchical logistic regression models. None of the interactions between childhood financial situation and age or sex reached significance and, therefore, were not included in the models fitted to evaluate the socio-economic factors related to 12month MDD (dependent variable). In the unadjusted models (model 1), having lower levels of education, occupation skill, household income and childhood financial situation were significantly associated with a higher probability of 12-month MDD. The size of these associations decreased in model 2 (after adjusting for the presence of all socioeconomic variables), although they remained significant except for having a bad childhood financial situation, which was no longer significant. In the full adjusted model (Model 3), only 
quartile 1 of income, having no studies, never having worked and reporting a very bad childhood financial situation remained significantly associated with 12-month MDD. The unadjusted ordered logistic regression model (Table 3) showed a gradient in all socioeconomic markers, according to which, the worse the childhood financial situation, the worse the socioeconomic markers during adulthood, particularly in the case of education level.

The results from the mediation analyses on depression are shown in Table 4. All mediated percentages were considered non-significant except for education level. According to these analyses, education level significantly explained about 34-38 per cent of the association between having a bad-very bad childhood financial situation and a higher likelihood of suffering from MDD during older adulthood, compared with those with a good/very good childhood financial situation.

\section{Discussion}

To the authors' knowledge, this is the first study to examine the link between childhood financial hardship and presence of depression after the age of 50, and how other socioeconomic indicators (education, occupation and income) during adulthood might fully or partially explain this association. First, we found that self-reporting a bad or very bad financial situation during childhood is associated with the presence of depression in older adults, even after adjusting for adulthood occupation, income, education, physical health and other social variables such as loneliness or number of close people. Second, participants' occupation, education level and household income are also independently associated with MDD in older adults, and this effect is beyond the effect of several covariates. And third, only education level achieved significantly mediated the impact of childhood financial hardship on late life MDD, specifically $37.3 \%$ of the effect of a bad 
childhood financial situation and $34.7 \%$ of the effect of a very bad situation compared with those with a good or very good childhood financial situation.

Previous studies have reported that low SES in childhood is a reliable predictor for the development of depression in younger adulthood (Gilman et al., 2003, 2002), midlife (Power et al., 2007; Stansfeld et al., 2008) and late life (Angelini et al., 2018; Tani et al., 2016). Some theoretical models have been proposed to explain the association between childhood hardship and latter health problems. The critical period model suggests that family income during childhood is related to a poorer cognitive development and emotional problems in children. This detrimental effect is thought to start early during the fetal period and the first years of the child, providing a basis for many of the health outcomes that are latter observed in adulthood (Glover, 2015; Najman et al., 2004). Our findings seem to support this theory and also suggest that the association between childhood financial situation and late-life depression is beyond the health status of older people.

Apart from this biological pathway, the intergenerational transmission of material deprivation from parents to children is also expected. According to the social pathways model the association between childhood financial hardship and late-life depression might be explained by the fact that children from socioeconomically disadvantaged families are more likely to continue to have lower SES later in life and therefore they might be more likely to be exposed to a greater number of stressful life events or bad housing conditions (Luo and Waite, 2005; Stansfeld et al., 2008). However, the fact that we found that it is participants' education level, but not income, that mediates the impact of childhood financial hardship on late life depression would indicate that this intergenerational transmission occurs through a limited access to higher education for these children, regardless of whether it is accompanied by material deprivation. The interpretation of these 
results should be considered under the particular social, political and historical context that this older cohort lived during their childhood and adolescence. Older participants (those aged 70+) were exposed to the Civil War that took place in Spain from 1936 to 1939 , whereas those younger respondents (i.e., 50 to 65 years old) were born during the post-war period, characterized by a dictatorship which took place from 1939 to 1975. During this period, the political and financial problems limited educational opportunities, especially for those children from disadvantages families and women, who were limited to learning domestic economy and needlework. After the restoration of democracy in the late 70's, access to primary secondary and university levels of school was ensured and universal (Flecha-García, 2011). Thus, it is possible that different results are found in younger cohorts. However, we explored the potential moderate role of age and sex, without finding significant results. Our findings are of particular interest in understanding the role of education in Spanish intergenerational social mobility. Other authors have already pointed out the importance of access to education as a mechanism for promoting social mobility in Spanish society (Pascual, 2009).

Additionally, it would be necessary to analyze the effect of socio-economic situation at country level in order to better understand the social pathways between childhood financial situation and late life depression. For example, a previous study compared countries according to their Gini coefficient and found that 0.3 is a potential threshold over which the impact of income inequality on health may become significantly higher (Kondo et al., 2012). This could explain the results of a previous study according to which living in Spain is a factor risk for MDD among older adults compared with Finland and Poland and after controlling the association by individual socioeconomic factors (Domènech-Abella et al., 2018). Thus, the association between childhood financial 
situation and late-life depression could be also due to contextual factors such as social inequality and the availability of public policies aimed at alleviating their effects.

\section{Strengths and limitations of the study}

The strengths of our study include the use of community-representative sample of older adults from a wide range of socioeconomic backgrounds and the ability to control for several confounding factors. However, some limitations should be kept in mind. First, the cross-sectional design limited the possibility of examining causal relationships. However, following the natural chronological order of the variables may help to compensate for this to some extent by using the financial situation during childhood, then time invariant factors such as educational level and highest occupation skill (which usually are reached during younger adulthood) and finally, the independent variable, MDD during the last year (i.e., older adulthood). Second, some of the variables were collected retrospectively through selfreport, which may result in recall or reporting bias. However, recall biases are usually relatively minor in epidemiological studies regarding the presence of specific chronic diseases and the influence of patient characteristics, including socioeconomic factors and depressive symptomatology (Kriegsman et al., 1996). Previous studies tried to approach to the childhood financial situation through the educational and occupational level of parents. These measures might provide a lower risk of bias derived from retrospectively collecting the information through self-report. However, these variables are not necessarily related to a bad financial situation. Finally, since the association between socioeconomic status indicators and mental health is thought to vary between countries, the results of the present study could not be generalized. However, they provide a better understanding of the Spanish situation and suggest the necessity of replicating this study in other countries. 


\section{Conclusion}

Our findings are of interest in understanding the complex association between childhood socioeconomic circumstances and depression in older adults. Older Spanish adults with a very bad childhood financial situation are 11 times more likely to obtain a lower level of education than those with good childhood financial situation and 3 times more likely to suffer from MDD. Education level mediates about $40 \%$ of the association between childhood financial hardship and older adult depression. Therefore, improving access to the educational system during the life course might result in a reduction in the prevalence of depression late in life, and particularly among individuals with low SES. Future studies with longitudinal data are needed to replicate this study in different cohorts and countries, taking into consideration various demographic, cultural, socio-economic and health characteristics.

\section{References}

Allen, J., Balfour, R., Bell, R., Marmot, M., 2014. Social determinants of mental health. International review of psychiatry, 26, 392-407.

American Psychiatric Association, 2013. Diagnostic and statistical manual of mental disorder (5th ed.), DC: Author. ed. Washington.

Angelini, V., Howdon, D.D.D., Mierau, J.O., 2018. Childhood Socioeconomic Status and

Late-Adulthood Mental Health: Results from the Survey on Health, Ageing and Retirement in Europe. J. Gerontol. B. Psychol. Sci. Soc. Sci. [in press]

Basu, S., Millett, C., 2013. Social Epidemiology of Hypertension in Middle-Income CountriesNovelty and Significance. Hypertension 62, 280-287.

Ben-Shlomo, Y., Kuh, D., 2002. A life course approach to chronic disease epidemiology: conceptual models, empirical challenges and interdisciplinary perspectives. Int. J. 
Epidemiol. 31, 285-93.

Blazer, D.G., 2003. Depression in late life: Review and commentary. Journals Gerontol. Ser. A Biol. Sci. Med. Sci. 58, 249-65.

Breen, R., Karlson, K.B., Holm, A., 2013. Total, Direct, and Indirect Effects in Logit and Probit Models. Sociol. Methods Res. 42, 164-191.

Byers, A.L., Yaffe, K., Covinsky, K.E., Friedman, M.B., Bruce, M.L., 2010. High Occurrence of Mood and Anxiety Disorders Among Older Adults. Arch. Gen. Psychiatry 67, 489-496.

Clark, A. M., DesMeules, M., Luo, W., Duncan, A. S., Wielgosz, A., 2009. Socioeconomic status and cardiovascular disease: risks and implications for care. Nature Reviews Cardiology, 6, 712-722.

Conroy, K., Sandel, M., Zuckerman, B., 2010. Poverty grown up: how childhood socioeconomic status impacts adult health. J. Dev. Behav. Pediatr. 31, 154-60.

Djernes, J.K., 2006. Prevalence and predictors of depression in populations of elderly: A review. Acta Psychiatr. Scand. 113, 372-387.

Domènech-Abella, J., Lara, E., Rubio-Valera, M., Olaya, B., Moneta, M.V., Rico-Uribe,et al., 2017. Loneliness and depression in the elderly: the role of social network, Soc Psychiatry Psychiatr Epidemiol. 52, 381-390.

Domènech-Abella, J., Mundó, J., Leonardi, M., Chatterji, S., Tobiasz-Adamczyk, B., Koskinen, S., et al., 2018. The association between socioeconomic status and depression among older adults in Finland, Poland and Spain: A comparative crosssectional study of distinct measures and pathways. J. Affect. Disord. 241, 311-318.

Elovainio, M., Rosenström, T., Hakulinen, C., Pulkki-Råback, L., Mullola, S., Jokela, M., et al., 2016. Educational attainment and health transitions over the life course: testing 
the potential mechanisms. J. Public Health (Bangkok). 38, e254-e262.

European Union, 2009. Commission recommendation of 29 October 2009 on the use of the International Standard Classification of Occupations (ISCO-08). Off. J. Eur. Union L $292,31-47$.

Eurostat, 2008. Risk of poverty after social transfers [WWW Document]. URL

http://ec.europa.eu/eurostat/tgm/table.do?tab=table \&init=1\&plugin=1\&pcode=t2020_ $52 \&$ language $=$ en

Flecha-García, C. 2011. Education in Spain: Close-up of its history in the 20th century. Analytical Reports in International Education. 4, 17-42.

Gabilondo, A., Rojas-Farreras, S., Vilagut, G., Haro, J.M., Fernández, A., Pinto-Meza, A., Alonso, J., 2010. Epidemiology of major depressive episode in a southern European country: Results from the ESEMeD-Spain project. J. Affect. Disord. 120, 76-85.

Galobardes, B., Lynch, J.W., Davey Smith, G., 2004. Childhood socioeconomic circumstances and cause-specific mortality in adulthood: systematic review and interpretation. Epidemiol. Rev. 26, 7-21.

Garin, N., Koyanagi, A., Chatterji, S., Tyrovolas, S., Olaya, B., Leonardi, M., et al., Haro, J.M., 2016. Global Multimorbidity Patterns: A Cross-Sectional, Population-Based, Multi-Country Study. J. Gerontol. A. Biol. Sci. Med. Sci. 71, 205-14.

Gilman, S.E., Kawachi, I., Fitzmaurice, G.M., Buka, S.L., 2003. Family Disruption in Childhood and Risk of Adult Depression. Am. J. Psychiatry 160, 939-946.

Gilman, S.E., Kawachi, I., Fitzmaurice, G.M., Buka, S.L., 2002. Socioeconomic status in childhood and the lifetime risk of major depression. Int. J. Epidemiol. 31, 359-67.

Glover, V., 2015., Prenatal Stress and Its Effects on the Fetus and the Child: Possible Underlying Biological Mechanisms. In: Antonelli M. (eds) Perinatal Programming of 
Neurodevelopment. Advances in Neurobiology, vol 10. Springer, New York, NY

Haro, J.M., Arbabzadeh-Bouchez, S., Brugha, T.S., De Girolamo, G., Guyer, M.E., Jin, R., et al., 2006. Concordance of the Composite International Diagnostic Interview Version 3.0 (CIDI 3.0) with standardized clinical assessments in the WHO World Mental Health Surveys. Int. J. Methods Psychiatr. Res. 15, 167-180.

International Labour Organization, 2008. International Standard Classification of Occupations (ISCO-08) - Conceptual Framework. ILO, Annexe 1 (http:// www.ilo.org/public/english/bureau/stat/isco/docs/annex1.doc).

Hughes, M.E., Waite, L.J., Hawkley, L.C., Cacioppo, J.T., 2004. A Short Scale for Measuring Loneliness in Large Surveys: Results From Two Population-Based Studies. Res. Aging 26, 655-672.

Karlson, K.B., Holm, A., 2011. Decomposing primary and secondary effects: A new decomposition method. Res. Soc. Stratif. Mobil. 29, 221-237.

Karlson, K.B., Holm, A., Breen, R., 2012. Comparing Regression Coefficients Between Same-sample Nested Models Using Logit and Probit. Sociol. Methodol. 42, 286-313.

Kendig, H., Loh, V., O’Loughlin, K., Byles, J., Nazroo, J.Y., 2016. Pathways to WellBeing in Later Life: Socioeconomic and Health Determinants Across the Life Course of Australian Baby Boomers. J. Popul. Ageing 9, 49-67.

Kessler, R. C., \& Üstün, T. B., 2004. The world mental health (WMH) survey initiative version of the world health organization (WHO) composite international diagnostic interview (CIDI). International journal of methods in psychiatric research, 13, 93-121.

Kondo, N., Dam, R.M. Van, Sembajwe, G., Subramanian, S. V, Kawachi, I., Yamagata, Z., 2012. Income inequality and health: the role of population size, inequality threshold, period effects and lag effects. J Epidemiol Community Health. 66, e11. 
Koster, A., Bosma, H., Kempen, G.I.J.M., Penninx, B.W.J.H., Beekman, A.T.F., Deeg, D.J.H., et al., 2006. Socioeconomic differences in incident depression in older adults: The role of psychosocial factors, physical health status, and behavioral factors. J. Psychosom. Res. 61, 619-627.

Kriegsman, D.M.W., Penninx, B.W.J.H., Van Eijk, J.T.M., Boeke, A.J.P., Deeg, D.J.H., 1996. Self-reports and general practitioner information on the presence of chronic diseases in community dwelling elderly. J. Clin. Epidemiol. 49, 1407-1417.

Lee, J., 2011. Pathways from education to depression. J. Cross. Cult. Gerontol. 26, 121135.

Leonardi, M., Chatterji, S., Koskinen, S., Ayuso-Mateos, J.L., Haro, J.M., Frisoni, G., et al., Gmurek, M., Serrano, R., Finocchiaro, C., 2014. Determinants of Health and Disability in Ageing Population: The COURAGE in Europe Project (Collaborative Research on Ageing in Europe). Clin. Psychol. Psychother. 21, 193-198.

Luo, Y., \& Waite, L. J., 2005. The impact of childhood and adult SES on physical, mental, and cognitive well-being in later life. J Gerontol B Psychol Sci Soc Sci, 60, S93-S101.

Mancia, G., Fagard, R., Narkiewicz, K., Redón, J., Zanchetti, A., Böhm, M., et al., 2013. 2013 ESH/ESC Guidelines for the management of arterial hypertension. J. Hypertens. $31,1281-1357$.

Marmot, M., 2005. Social determinants of health inequalities. The lancet, 365, 1099-1104.

Moussavi, S., Chatterji, S., Verdes, E., Tandon, A., Patel, V., Ustun, B., 2007. Depression, chronic diseases, and decrements in health: results from the World Health Surveys. Lancet (London, England) 370, 851-858.

Najman, J.M., Aird, R., Bor, W., O’Callaghan, M., Williams, G.M., Shuttlewood, G.J., 2004. The generational transmission of socioeconomic inequalities in child cognitive 
development and emotional health. Soc. Sci. Med. 58, 1147-58.

Pascual, M., 2009. Intergenerational income mobility: The transmission of socio-economic status in Spain. J. Policy Model. 31, 835-846.

Ploubidis, G.B., Grundy, E., 2009. Later-life mental health in Europe: a country-level comparison. J. Gerontol. B. Psychol. Sci. Soc. Sci. 64, 666-76.

Poulton, R., Caspi, A., Milne, B.J., Thomson, W.M., Taylor, A., Sears, M.R., et al., 2002. Association between children's experience of socioeconomic disadvantage and adult health: a life-course study. Lancet (London, England) 360, 1640-5.

Power, C., Atherton, K., Strachan, D.P., Shepherd, P., Fuller, E., Davis, A., et al., 2007. Life-course influences on health in British adults: effects of socio-economic position in childhood and adulthood. Int. J. Epidemiol. 36, 532-9.

Pudrovska, T., Logan, E.S., Richman, A., 2014. Early-life social origins of later-life body weight: The role of socioeconomic status and health behaviors over the life course. Soc. Sci. Res. 46, 59-71.

Rubin, D.B., 2004. Multiple imputation for nonresponse in surveys. Wiley-Interscience.

Stansfeld, S.A., Clark, C., Rodgers, B., Caldwell, T., Power, C., 2008. Childhood and adulthood socio-economic position and midlife depressive and anxiety disorders. Br. J. Psychiatry 192, 152-153.

StataCorp, 2013. Stata Statistical Software: Relase 13. Statacorp LP, College Station, TX. Tani, Y., Fujiwara, T., Kondo, N., Noma, H., Sasaki, Y., Kondo, K., 2016. Childhood Socioeconomic Status and Onset of Depression among Japanese Older Adults: The JAGES Prospective Cohort Study. Am. J. Geriatr. Psychiatry 24, 717-726.

White, I. R., Royston, P., Wood, A. M., 2011. Multiple imputation using chained equations: issues and guidance for practice. Statistics in medicine, 30, 377-399. 
Table 1. Characteristics of the study sample

\begin{tabular}{|c|c|c|c|c|}
\hline & $\begin{array}{l}\text { Overall } \\
n=3623\end{array}$ & $\begin{array}{l}\text { No MDD } \\
3189(87.9 \%) \\
\end{array}$ & $\begin{array}{l}\text { MDD } \\
434(12.1 \%) \\
\end{array}$ & $p$-value \\
\hline \multicolumn{5}{|l|}{ Age groups } \\
\hline $50-64$ & $1760(47.0)$ & $1558(47.1)$ & $202(46.6)$ & 0.958 \\
\hline $65-79$ & $1485(41.8)$ & $1297(41.8)$ & $188(41.7)$ & \\
\hline $80+$ & $378(11.2)$ & $334(11.1)$ & $44(11.7)$ & \\
\hline Female* & $1981(53.8)$ & $1664(50.9)$ & $317(74.4)$ & $<0.001$ \\
\hline \multicolumn{5}{|l|}{ Household income } \\
\hline Quartile 1 (highest) & $660(25.0)$ & $599(26.4)$ & $61(15.9)$ & $<0.001$ \\
\hline Quartile 2 & $701(26.2)$ & $623(26.9)$ & $78(21.6)$ & \\
\hline Quartile 3 & $597(23.1)$ & $518(23.3)$ & $79(22.3)$ & \\
\hline Quartile 4 (lowest) & $646(25.7)$ & $525(23.5)$ & $121(40.2)$ & \\
\hline \multicolumn{5}{|l|}{ Education level } \\
\hline Tertiary & $393(10.7)$ & $378(11.4)$ & $15(5.7)$ & $<0.01$ \\
\hline Secondary & $949(25.5)$ & $863(26.1)$ & $86(20.6)$ & \\
\hline Primary & $1075(31.3)$ & $968(32.1)$ & $107(25.2)$ & \\
\hline No formal education & $1206(32.6)$ & $980(30.4)$ & $226(48.6)$ & \\
\hline \multicolumn{5}{|l|}{ Occupation skill } \\
\hline High & $660(20.1)$ & $616(21.1)$ & $44(11.8)$ & $<0.001$ \\
\hline Medium & $1495(48.4)$ & $1351(49.3)$ & $144(42.1)$ & \\
\hline Low & $523(16.7)$ & $434(16.0)$ & $89(22.3)$ & \\
\hline Never worked & $481(14.8)$ & $388(13.6)$ & $93(23.8)$ & \\
\hline \multicolumn{5}{|l|}{$\begin{array}{l}\text { Childhood financial } \\
\text { situation }\end{array}$} \\
\hline Good / very good & $854(22.7)$ & $781(23.7)$ & $73(15.8)$ & $<0.001$ \\
\hline Normal & $1628(45.2)$ & $1467(46.5)$ & $161(35.6)$ & \\
\hline $\mathrm{Bad}$ & $849(24.3)$ & $716(23.2)$ & $133(32.4)$ & \\
\hline Very bad & $281(7.8)$ & $216(6.6)$ & $65(16.2)$ & \\
\hline $\begin{array}{l}\text { Loneliness (3-9) } \\
\text { Mean (CI 95\%) }\end{array}$ & $3.74(3.66,3.81)$ & $3.55(3.48,3.62)$ & $5.08(4.77,5.40)$ & $<0.001$ \\
\hline \multicolumn{5}{|l|}{ Close people } \\
\hline More than 5 & $1640(46.2)$ & $1475(47.1)$ & $165(39.2)$ & $<0.01$ \\
\hline 3 to 5 & $1210(35.1)$ & $1083(35.5)$ & $127(32.0)$ & \\
\hline 1 or 2 & $590(16.8)$ & $486(15.8)$ & $104(25.0)$ & \\
\hline None & $62(1.9)$ & $51(1.7)$ & $11(3.8)$ & \\
\hline \multicolumn{5}{|l|}{ Chronic conditions } \\
\hline 0 & $1398(38.6)$ & $1310(40.9)$ & $88(21.5)$ & $<0.001$ \\
\hline 1 & $1191(32.3)$ & $1059(32.8)$ & $132(28.3)$ & \\
\hline 2 & $672(18.6)$ & $559(17.7)$ & $113(25.0)$ & \\
\hline More than 2 & $362(10.5)$ & $261(8.5)$ & $101(25.2)$ & \\
\hline $\begin{array}{l}\text { Depression before } \\
50 \mathrm{y}^{*}\end{array}$ & $356(10.0)$ & $233(7.4)$ & $123(28.5)$ & $<0.001$ \\
\hline
\end{tabular}

Unweighted frequencies (n) and weighted proportions are displayed unless otherwise indicated. Some percentages are based on an incomplete sample because of missing data. The difference in sample characteristics between depression groups was tested by $\chi^{2}$ tests and Student $t$ tests for categorical and continuous variables, respectively. ${ }^{*}$ Categories of reference: male, without financial strains and without diagnosed depression earlier than 50 years old. $\mathrm{MDD}=$ major depressive disorder during last year; $\mathrm{CI}=$ confidence interval 
Table 2. Hierarchical logistic regression models for the presence of 12-month MDD

\begin{tabular}{|c|c|c|c|}
\hline & Model 1 & Model 2 & Model 3 \\
\hline \multicolumn{4}{|l|}{ Household income } \\
\hline Quartile 1 (highest) & Ref. & Ref. & Ref. \\
\hline Quartile 2 & $1.28(0.92,1.80)$ & $1.05(0.74,1.49)$ & $1.07(0.73,1.58)$ \\
\hline Quartile 3 & $1.60(1.15,2.23)^{*}$ & $1.11(0.78,1.58)$ & $1.05(0.70,1.56)$ \\
\hline Quartile 4 (lowest) & $2.38(1.72,3.29)^{* *}$ & $1.56(1.10,2.20)$ & $1.53(1.03,2.26)$ \\
\hline \multicolumn{4}{|l|}{ Education level } \\
\hline Tertiary & Ref. & Ref. & Ref. \\
\hline Secondary & $2.51(1.43,4.40)^{*}$ & $2.03(1.13,3.66)$ & $1.74(0.92,3.27)$ \\
\hline Primary & $2.79(1.60,4.84)^{* *}$ & $1.92(1.05,3.50)$ & $1.60(0.84,3.05)$ \\
\hline No formal education & $5.81(3.40,9.93)^{* *}$ & $3.09(1.69,5.64)^{* *}$ & $2.59(1.34,5.00)^{*}$ \\
\hline \multicolumn{4}{|l|}{ Occupation skill } \\
\hline High & Ref. & Ref. & Ref. \\
\hline Medium & $1.63(1.16,2.29)^{*}$ & $1.16(0.80,1.69)$ & $1.19(0.80,1.79)$ \\
\hline Low & $2.81(1.93,4.09)^{* *}$ & $1.61(1.06,2.44)$ & $1.14(0.71,1.83)$ \\
\hline Never worked & $3.37(2.33,4.88)^{* *}$ & $2.07(1.36,3.13)^{*}$ & $1.67(1.04,2.68)$ \\
\hline \multicolumn{4}{|l|}{$\begin{array}{l}\text { Childhood financial } \\
\text { situation }\end{array}$} \\
\hline Good/very good & Ref. & Ref. & Ref. \\
\hline Normal & $1.17(0.88,1.57)$ & $1.03(0.77,1.39)$ & $1.19(0.79,1.51)$ \\
\hline Bad & $1.99(1.47,2.69)^{* *}$ & $1.41(1.02,1.95)$ & $1.54(1.07,2.20)$ \\
\hline Very bad & $3.22(2.23,4.65)^{* *}$ & $2.09(1.41,3.10)^{* *}$ & $1.95(1.25,3.04)^{*}$ \\
\hline
\end{tabular}

Table 3. Ordered logistic regression models of the association between childhood financial situation and socioeconomic factors in adulthood.

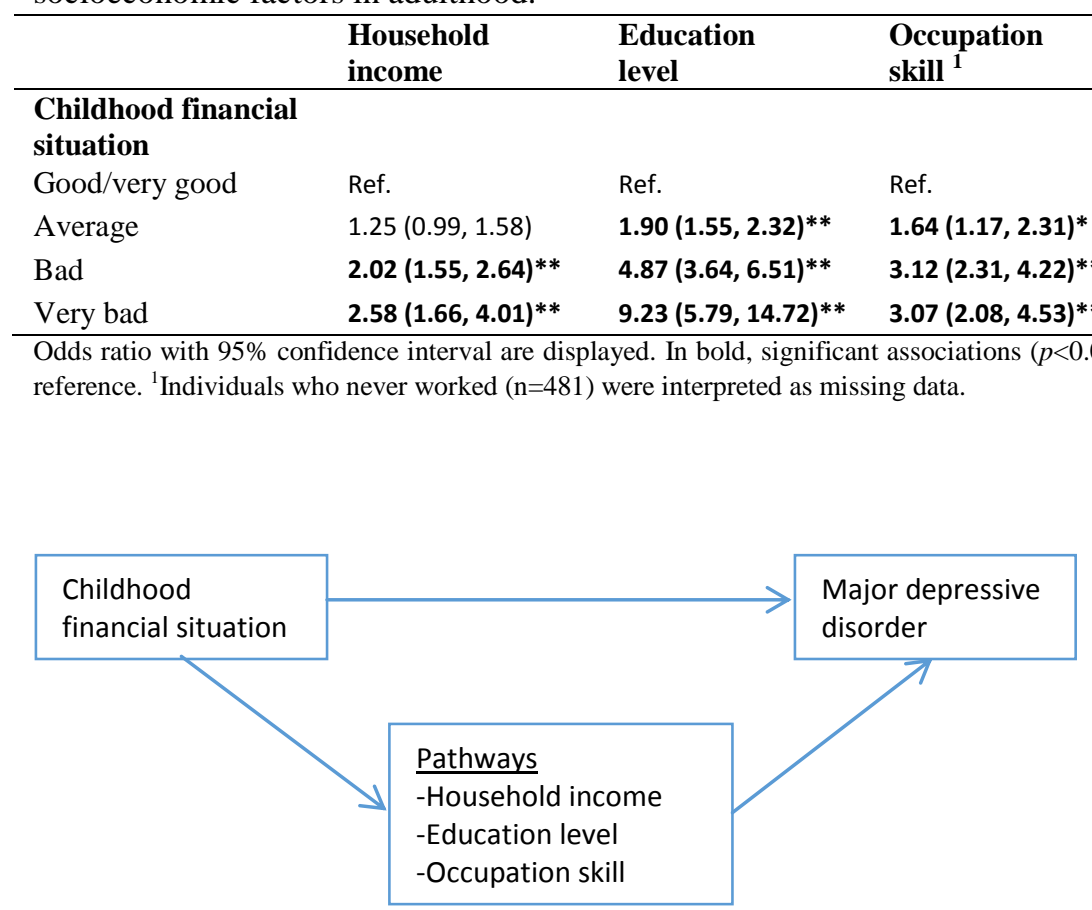

Fig. 1. Hypothesized mediation model predicting major depressive disorder in late life. 
Table 4. Logistic regression analyses of the association between childhood financial situation and 12-month MDD and socioeconomic factors during adulthood as mediators (KHB method).

\begin{tabular}{|c|c|c|c|c|}
\hline \multirow{2}{*}{$\begin{array}{l}\text { Independent variable: } \\
\text { Childhood financial } \\
\text { situation } \\
\text { (ref: Good/very good) }\end{array}$} & \multicolumn{2}{|c|}{$\begin{array}{l}\text { Mediator variable: } \\
\text { Household Income }\end{array}$} & \multicolumn{2}{|c|}{$\begin{array}{l}\text { Mediator variable: } \\
\text { Education level }\end{array}$} \\
\hline & $\begin{array}{l}\text { Coefficient } \\
(95 \% \text { CI })\end{array}$ & $\begin{array}{c}\% \\
\text { Mediated } \\
\end{array}$ & $\begin{array}{l}\text { Coefficient } \\
(95 \% \text { CI })\end{array}$ & $\begin{array}{c}\% \\
\text { Mediated } \\
\end{array}$ \\
\hline \multicolumn{5}{|l|}{ Bad } \\
\hline Total & $0.67(0.32,1.01)^{* *}$ & & $0.67(0.32,1.01)^{* *}$ & \\
\hline Direct & $0.59(0.25,0.94)^{*}$ & & $0.42(0.06,0.77)$ & \\
\hline Indirect & $0.07(-0.04,0.19)$ & $10.4 \%$ & $0.25(0.07,0.43)^{*}$ & $37.3 \%$ \\
\hline \multicolumn{5}{|l|}{ Very bad } \\
\hline Total & $0.96(0.53,1.38)^{* *}$ & & $1.00(0.57,1.43)^{* *}$ & \\
\hline Direct & $0.87(0.44,1.30)^{* *}$ & & $0.65(0.21,1.09)^{*}$ & \\
\hline \multirow[t]{2}{*}{ Indirect } & $0.09(-0.03,0.20)$ & $9.4 \%$ & $0.35(0.15,0.54)^{*}$ & $34.7 \%$ \\
\hline & \multicolumn{2}{|c|}{$\begin{array}{l}\text { Mediator variable: } \\
\text { Occupation skill }\end{array}$} & \multicolumn{2}{|c|}{$\begin{array}{c}\text { Mediator variables: } \\
\text { All mediators }\end{array}$} \\
\hline \multicolumn{5}{|l|}{ Bad } \\
\hline Total & $0.67(0.33,1.02)^{* *}$ & & $0.69(0.34,1.04)^{* *}$ & \\
\hline Direct & $0.60(0.26,0.95)^{*}$ & & $0.42(0.06,0.78)$ & \\
\hline Indirect & $0.07(-0.05,0.19)$ & $10.4 \%$ & $0.27(0.06,0.47)$ & $39.1 \%$ \\
\hline \multicolumn{5}{|l|}{ Very bad } \\
\hline Total & $0.98(0.55,1.40)^{* *}$ & & $1.01(0.58,1.44)^{* *}$ & \\
\hline Direct & $0.91(0.48,1.34)^{* *}$ & & $0.66(0.21,1.11)^{*}$ & \\
\hline Indirect & $0.06(-0.05,0.18)$ & $6.1 \%$ & $0.35(0.12,0.57)^{*}$ & $34.7 \%$ \\
\hline
\end{tabular}

NOTE: All models are adjusted for age, gender, number of close people, loneliness, number of chronic conditions, and depression before the age of 50. In bold, significant associations and proportions $\left(p<0.05,{ }^{*} p<0.01, * * p<0.001\right)$. CI $=$ confidence interval; ref $=$ category of reference

\section{Supplementary material}

Table S1. Proportion of missingness for variables included in the multiple imputation model

\begin{tabular}{lc}
\hline & $\begin{array}{c}\mathrm{n}(\%) \\
\text { missingness }\end{array}$ \\
\hline Variables used in the regression models & $348(9.6)$ \\
Occupation & $1019(28.1)$ \\
Income (quartiles) & $11(0.3)$ \\
Childhood financial situation & $90(2.48)$ \\
Loneliness & $34(0.94)$ \\
Close people & 0 \\
Education level & 0 \\
Age groups & 0 \\
Gender & 0 \\
Number of chronic conditions & 0 \\
Depression before 50 years old & 0 \\
12-month major depressive disorder & \\
Auxiliary variables & 0 \\
Marital status & 0 \\
Daily smoker (never, in the past, current) & 0 \\
Sedentary (yes vs. no) & 0 \\
Obesity (yes vs. no) & 0 \\
Financial strains (yes vs. no) & 0 \\
Subjective social status (0-10) & 0 \\
Private health care (yes vs. no) &
\end{tabular}




\section{Funding}

The research leading to these results has received funding from the European Community's Seventh Framework Programme (FP7/2007-2013) under grant agreement number 223071 (COURAGE in Europe), from the Instituto de Salud Carlos III-FIS (grant numbers PS09/01845 and PS09/00295), and from the Spanish Ministry of Science, Innovation and Universities (MCIU) (grant number ACI2009-1010). The study was supported by the Centro de Investigación Biomédica Red de Salud Mental (CIBERSAM), Instituto de Salud Carlos III, Madrid, Spain, together with the PGC2018-094324-B-I00 research project, funded by the Ministry of Science, Innovation and Universities (MCIU), the State Research Agency (AEI) and the European Regional Development Fund (ERDF). Joan DomènechAbella's work is supported by the FPU predoctoral grant (FPU16/05209) from the Spanish Ministry of Education, Culture and Sports. Beatriz Olaya's work is supported by the PERIS program 2016-2020 "Ajuts per a la Incorporació de Científics i Tecnòlegs" [grant number SLT006/17/00066], with the support of the Generalitat de Catalunya Health Department. Funding sources had no involvement in study design; in the collection, analysis and interpretation of data; in the writing of the articles; and in the decision to submit it for publication. 